\title{
Key Technology Research on Quality Inspection and Evaluation of Orthoimage Used in China's National Land Survey
}

\author{
SHANG Yaoling a , Zhao Yousong a, *, MA Wei, WU Xuan, WANG Jindong, LUO Fujun, YAN \\ Qingqing,Xu Yongmin
}

${ }^{a}$ National Quality Inspection and Testing Center for Surveying and Mapping Products, Beijing 100830, China

shangyl@sbsm.gov.cn

Corresponding author: 2310931713@qq.com

\begin{abstract}
The third national land survey is based on orthoimages with the results of the second national land survey to investigate the land classification, area and ownership of the national land in order to comprehensively understand the status of land use and land resources changes, and to improve the level of delicacy management for national nature resources. Therefore, an important task to ensure the completion of the third national land survey is to the develop a set of technical methods applicable to the quality inspection on orthoimage of the third national land survey.

In view of the inapplicability of the existing inspection standards and technical methods of traditional basic surveying and mapping results on the orthoimage quality inspection of the third national land survey, The paper analyzes the orthoimage production characteristics and quality need of the third national land survey, improves the inspection quality elements, sampling strategy, inspection methods, evaluation methods and quality problem handling based on the existing inspection standards and technical methods by pilot, and puts forward the corresponding inspection standards and technical methods to promote the quality inspection of orthoimage on the third national land survey.
\end{abstract}

Compared with the traditional method, the application of this method in 2865 inspection of county-level's orthoimage of the third national land survey which covers the whole china, shows that, its inspection index is more reasonable, the inspection process is more scientific, the inspection efficiency is more efficient, and the direct cost of inspection is saved by $31 \%$.

Keywords: National Land Survey, Digital Orthoimage Map, Quality Inspection

\section{Introduction}

China conducts a nationwide land use survey every ten years, and it is the third time from 2018 to 2020. Main work contents: Firstly, investigate and verificate the distribution and utilization of cultivated land, garden land, forest land, grassland, commercial services, industrial and mining warehousing, housing, public management and services, transportation, water and facilities in the field; secondly, refine the investigation of cultivated land, and to learn more about the quantity, quality, distribution and composition of cultivated land; thirdly, investigate the inefficient idle land and find out the land use status within the scope of towns and development zones.

Based on the orthoimage produced by high-resolution remote sensing data, the national land survey makes full use of materials derived from the existing land survey, cadastral survey, and ownership registration, and adopts a combination methode of national quality control and the field survey and verification to accurately identify the type, area, ownership and distribution of each plot in China. It is based on the orthoimage map of the rural area with a resolution of better than $1 \mathrm{~m}$, and is based on the orthoimage map of the urban area with a resolution better than $0.2 \mathrm{~m}$. The orthoimage is corrected within 2018 by the time phase control and rectified by using highprecision digital elevation models, digital surface models and high-precision ground control points.

Based on the requirements of the national land survey and the production characteristics of the orthoimage, the paper analyzes the inapplicability of the previous quality inspection and evaluation standards, and proposes the quality inspection technical method to meet the need of the application of multi-source satellite data integration, widearea uncontrolled correction and regional network adjustment and multi-time phase color processing. The scheme of orthoimage quality inspection sampling is put forward based on the result studying on the orthoimage quality and uncertain factors. The quality evaluation technology is also put forward to meet the need of quality 
control and application of the focused land category of the national land survey.

The orthoimage quality inspection and evaluation technology proposed in this paper has been applied in the quality inspection and acceptance of orthoimage quality achievements in 2865 counties within 31 provinces and cities across China and shows that, the inspection technology is more practical, the quality element and subelement are more reasonable, the quality evaluation results are more scientific. the inspection efficiency is improved, and the quality reliability of the nationwide orthoimage achievements has also been guaranteed.

\section{Technical process and method}

\subsection{Technical process}

The quality inspection and acceptance process of the National Land Survey orthoimage achievements is carried out according to the data examining, the results receiving, the general check, the sampling, all entry inspection, some entry inspection, the quality fault tracking review, the unit quality evaluation of the unit achievement and quality judgment of the batch achievement ( see picture 1).

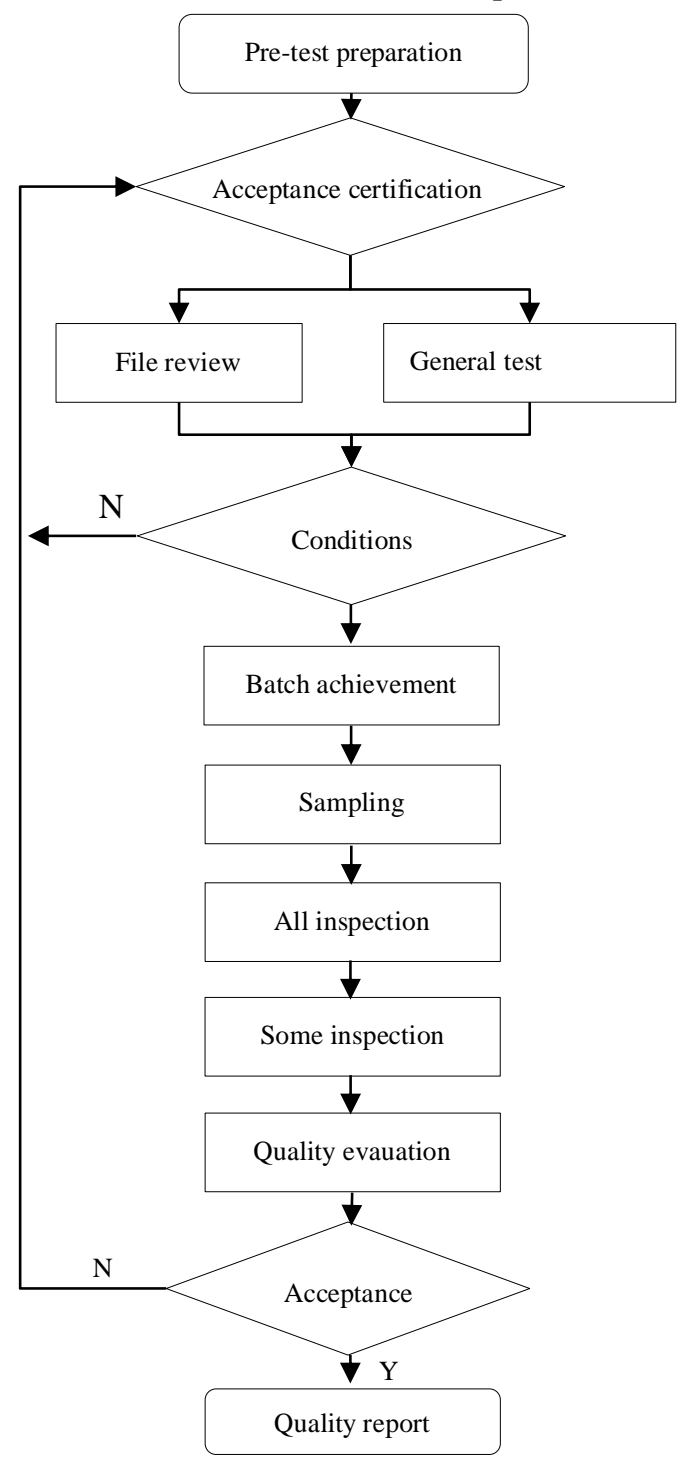

Fig.1 The Quality Inspection and Acceptance Process of the National Land Survey Orthoimage Image Achievements

\subsection{Quality Inspection and Acceptance method}

\subsubsection{Delaminating random sampling method based on results}

In order to solve the problem of universality and representativeness of sample selection, and to ensure the quality of the results of the regions represented by the sample quality, this paper adopts the inspection and acceptance method with the results of each province as the sampling plot and the county-level administrative scope as the sample unit. The Samples were sampled by delaminating random sampling method with the considering of combining with the characteristics of orthoimage production, the distribution of topographical land types, image source types, inter-county and interprovincial edge processing results, the coverage of 1:10,000 basic mapping results, focus classes areas of land survey, differences in technical capabilities of production units and other factors. A total of 294 county-level sample units were sampled in 31 sample plots across the country (the sample unit spatial distribution is shown in Figure 2 in each sampling plot and the yellow colour stands for the sample unit.)

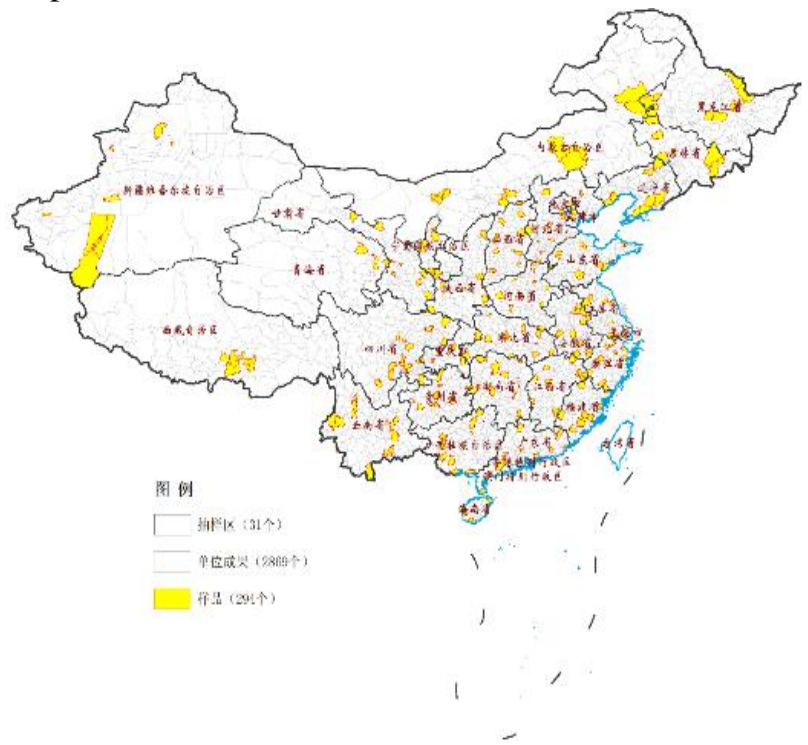

Fig. 2 The Sample Unit Distribution Map

\subsubsection{Position-accurate test method based on results classification}

In order to solve the problem of Position-accurate test of orthoimage achievements, and to ensure that the position accuracy of the orthoimage achievements meets the design requirements, according to the production method of orthoimages, this paper adopts the method of high accuracy test, the same accuracy test and field measurement to carry out the position accuracy test. For areas with high-precision surveying and mapping results, statistically calculate the error in plane position accuracy (greater than 30 points) by using existing high-precision, same-precision data results, large-scale map results, and other high-precision test points. For area of the none of high-precision data in the west, the accuracy test method 
suitable for large-area network adjustment control is adopted comprehensively; For the area of the results found to have quality fault or no reference data, the field measurement method is used to carry out the accuracy test.

\subsubsection{Comprehensive quality inspection and acceptance} method based on combination of checking software and human-computer interaction

In order to improve the efficiency quality inspection and acceptance of orthoimage achievements, comprehensive quality inspection and acceptance method based on combination of checking software and human-computer interaction has been adopted, for the check items which is suitable for machine inspection, such as geodetic coordinates, elevation reference, map projection, format consistency, current image time situation, resolution, grid parameters, metadata, and the topological relationships of mosaic block information file, are automatically checked by software; For the check items which is not suitable for machine test, such as edge proceeding, tone, the texture, high-level information, task coverage integrity, etc., are inspected by inspectors watching the screen at 1:20001:5000 scale of the image data ; For the key quality fault which need to be reviewed, use check-and-check method, the quality fault and the description of the orthoimage data quality will be recorded by generating spatial quality fault record data files and statistical tables.

\subsubsection{Automated quality evaluation method based on spatial quality fault database}

In order to better guarantee the quality of National Land Survey orthoimage image achievements, the national standard has been optimized and adjusted, the precision of the original image data, the ground resolution, the image edge proceeding accuracy and the inspection content of the mosaic block information file have been added to ensure the optimized adjustment test. Content and indicators (12 quality elements, 22 quality elements and 69 test entry) of quality inspection and acceptance of orthoimage achievements are well-defined. On this basis, the statistical calculation and acceptance of orthoimage quality faults have been solved, such as the statistical calculation of plane position accuracy and edge accuracy error, image noise and texture loss area, image information loss area, metadata and county mosaic block information file faults, etc. The automated quality assessment tool for the orthoimage quality fault based on the quality fault database has been developed and realized automated orthoimage quality evaluation and spatial management of orthoimage quality faults.

\section{The Image Quality Fault}

\subsection{Cloud shadow and blurred image}

Cloud shadows, snow, smoke and ice cover, blurred images, heavy shadows of mountains and buildings are found in individual image achievements, which has been solved by using the alternative orthoimage of the reproduction of re-ordering remote sensing images.

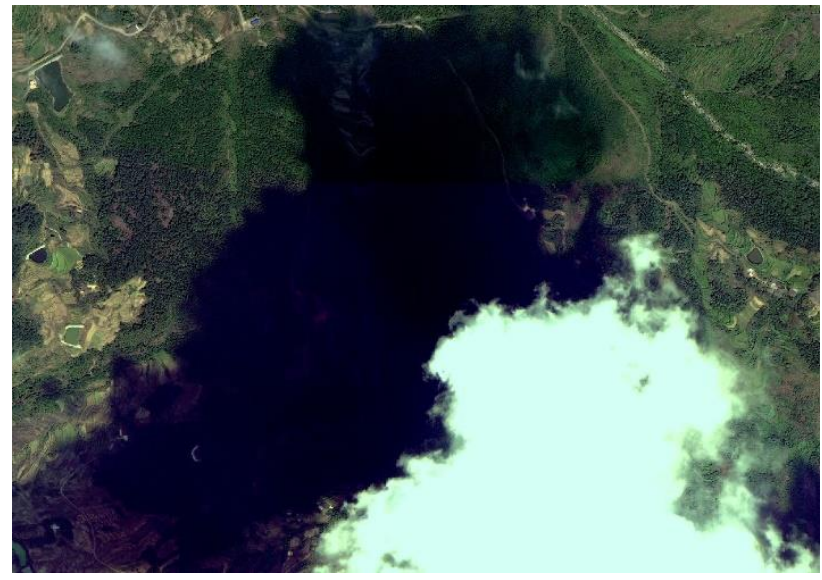

Cloud shadows

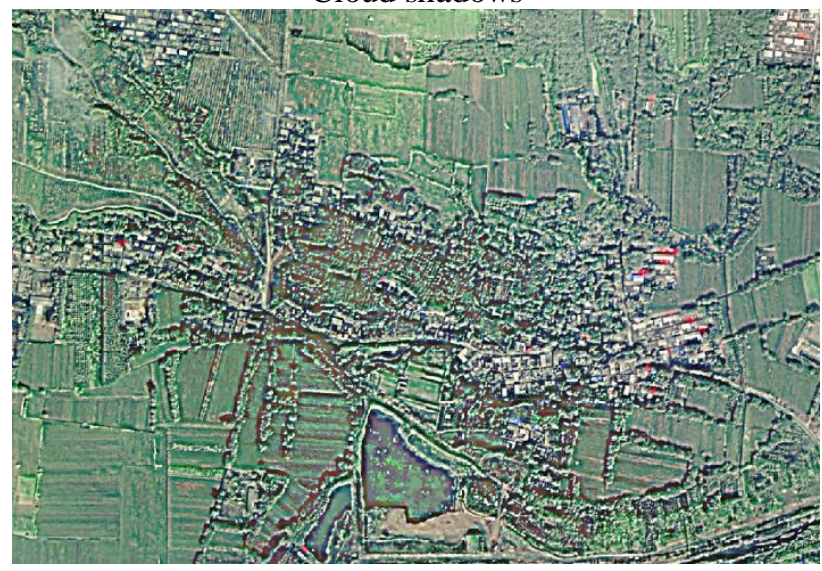

Blurred images

\subsection{Image texture or colour fault}

The image deformation of local building areas, roads, bridges, image smearing, ghosting, overexposure, strip noise, abnormal edge pixel values, etc., are found in individual orthoimage achievements, which has been solved by using re-production of image or by the technical process of the fault images.

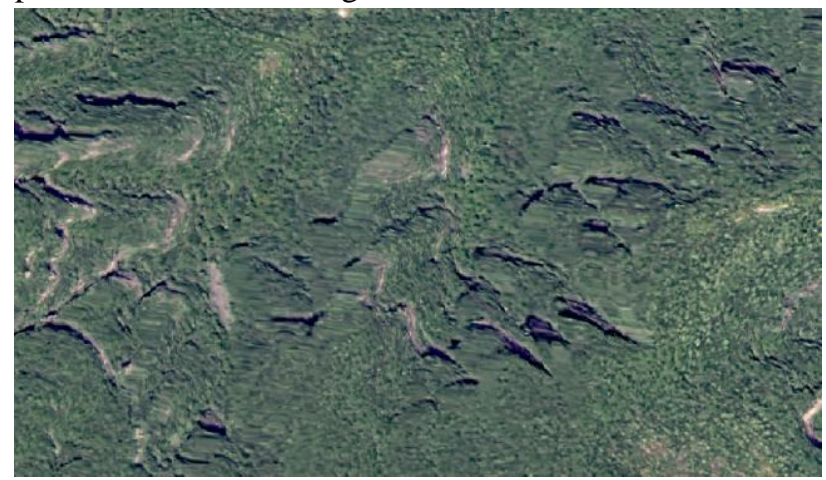

Image texture fault 


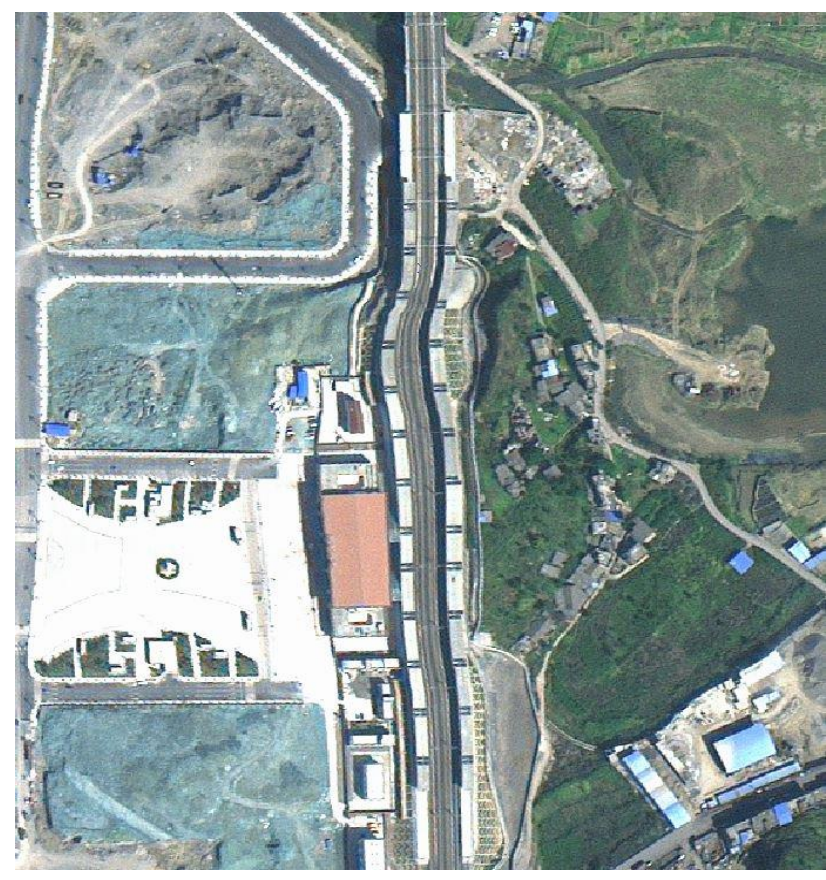

Image deformation of roads

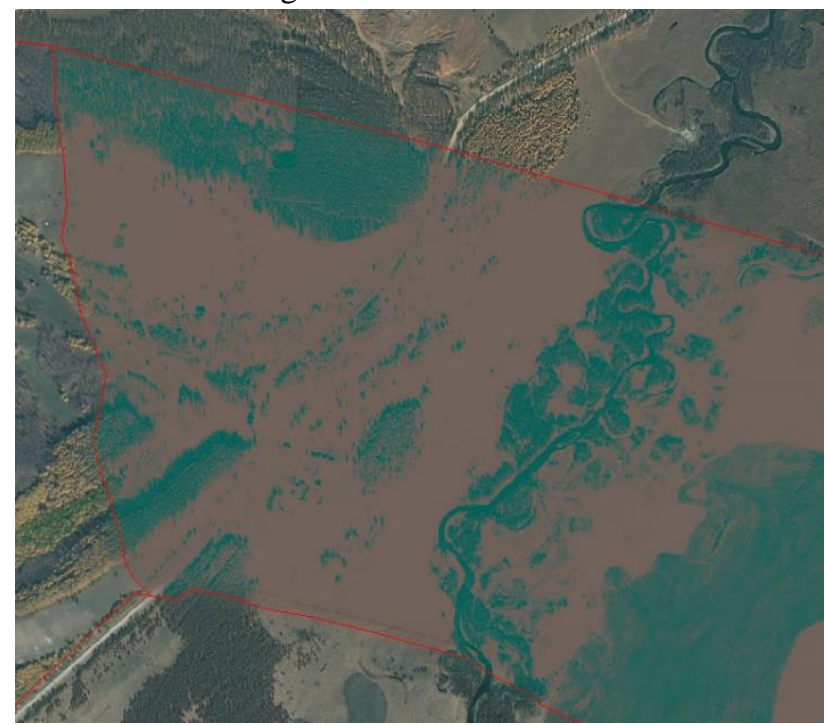

Image colour fault

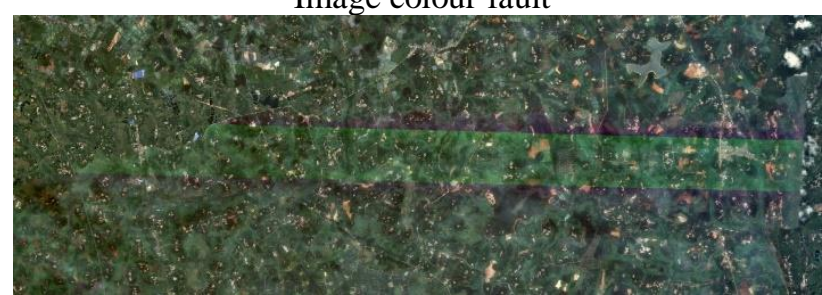

Image strip noise

\subsection{Image mosaic fault}

The line-like features of roads, bridges, and ridges are over-limited at the Image mosaic line, the edge line, and the county-level administrative boundary line , are found in individual image achievements, which has been solved by using re-production of image.

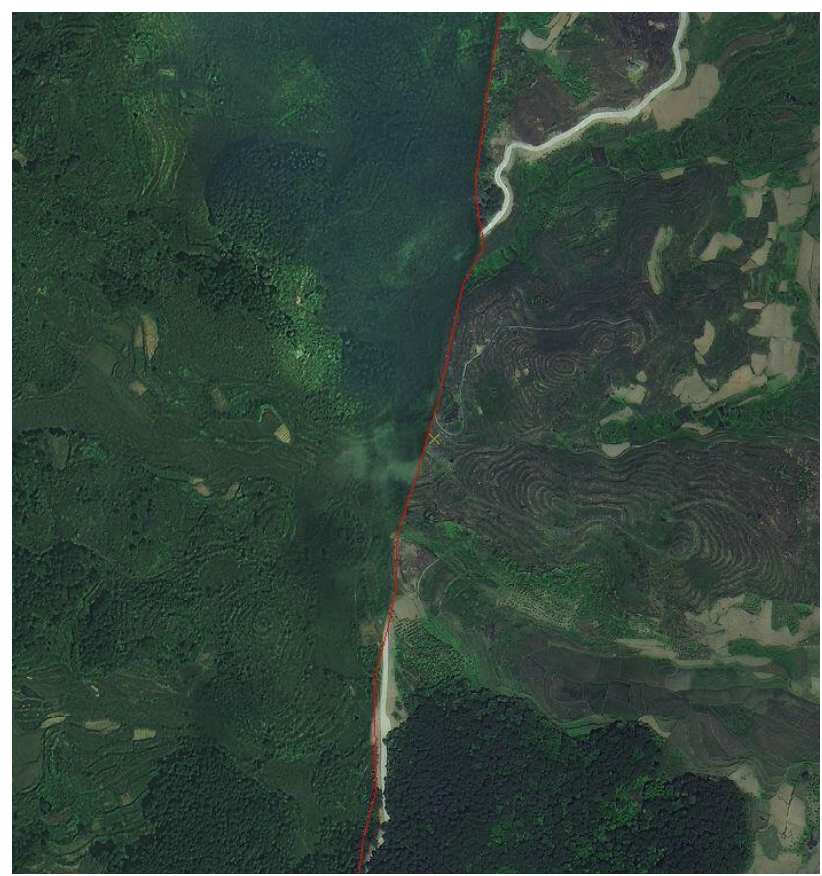

The missing of the road feature between edge joining

\section{Conclusion}

Key technology on quality inspection and evaluation of orthoimage used in China's National Land Survey proposed in this paper, has been applied to the production of 84 production units in 31 provinces and 2869 counties across China. During the period from January to December 2018, more than 40 full-time inspectors were organized by 5 inspection implementation teams, and 4,190 countylevel unit orthoimage archievements were reviewed and received, and 294 sampling orthoimage archievements were inspected and accepted. more than 20,000 quality faults has been inspected and 233 inspection opinions reports has been compiled. Finally, All the orthoimage archievements used in China's National Land Survey, meet the requirements of the technical design of the national project, in which the sample quality average score is 83.3 points, and the sample excellent rate reaches $87.8 \%$. The key technology research on quality inspection and evaluation of orthoimage proposed in this paper, not only solves how to give a guarantee of providing high-quality images for the national land survey, but also provide the reference of quatilty control, management, inspection, evaluation and acceptance for the other national project.

\section{References}

Liu, T. , Liu, H. , \& Qi, Y. . (2015). Construction land expansion and cultivated land protection in urbanizing china: insights from national land surveys, 1996-2006. Habitat International, 46, 13-22.

Peng, L. , He, C. T. , Gang, T. , \& Yang, L. . (2010). Research of multi-level land resources database construction based on county land resources survey data.

Searchinger, T., Heimlich, R., Houghton, R. A., Dong, F., Elobeid, A. , \& Fabiosa, J., et al. (2008). Use of u.s. croplands for biofuels increases greenhouse gases 
through emissions from land-use change. Science, 319(5867), 1238-1240.

Allan, J. D. . (2004). Landscapes and riverscapes: the influence of land use on stream ecosystems. Annual Review of Ecology Evolution and Systematics, 35(1), 257-284.

Lambin, E. F. , Geist, H. J. , \& Lepers, E. . (2003). Dynamics of land -use and land-cover change in tropical regions. Annu Rev Environ Res, 28(28), 205-241.

Kalnay, E. , \& Cai, M. . (2003). Impact of urbanization and land-use change on climate. Nature (London), 423(6939), 528-531.

Turner, B. L. I. , Skole, D. L. , Sanderson, S. , Fischer, G. , Fresco, L. , \& Leemans, R. . (1995). Land-use and land-cover change. science/research plan. Global Change Report (Sweden), 43(1995), 669-679.

Alonso, W. . (1964). Location and land use: toward a general theory of land rent. Economic Geography, 42(3).

Jetz, W. , Wilcove, D. S. , \& Dobson, A. P. . (2007). Projected impacts of climate and land-use change on the global diversity of birds. PLoS Biology, 5(6), e157.

Lambin, E. F. , Turner, B. L., Geist, H. J., Agbola, S. B. , Angelsen, A. , \& Bruce, J. W. , et al. (2001). The causes of land-use and land-cover change: moving beyond the myths. Global Environmental Change Part A: Human and Policy Dimensions, 11(4), 0-269. 